\title{
Study of the Influence of Biodiesel in Soot Emissions of Diesel Laminar Diffusion Flames
}

\author{
Lincoln Tolomelli e Tolomelli, ${ }^{*, a}$ Luiz G. Barreta, ${ }^{b}$ Pedro T. Lacava ${ }^{a}$ and \\ Dermeval Carinhana $\mathrm{Jr}^{b}$
}

\author{
anstituto Tecnológico de Aeronáutica, Praça Marechal Eduardo Gomes, 50, Vila das Acácias, \\ 12228-900 São José dos Campos-SP, Brazil \\ ${ }^{b}$ Instituto de Estudos Avançados, Trevo Cel. Av. José A. A. do Amarante, 1, Putim, \\ 12228-001 São José dos Campos-SP, Brazil
}

\begin{abstract}
In this work the presence of soot in laminar diffusion of diesel and blends diesel/biodiesel flames were investigated in the following proportions: 5, 10, 20 and 50\% of biodiesel. The technique of laser-induced incandescence (LII) was used for the soot detection. Horizontal mapping were performed at two heights ( 80 and $260 \mathrm{~mm}$ above the burner) to investigate the distribution of soot along the studied flames. The experiment was performed with a pulsed Nd:YAG laser with the wavelength of $1064 \mathrm{~nm}$. The results have shown that the soot emission decreases as the amount of biodiesel increases in the blends.
\end{abstract}

Keywords: laser-induced incandescence, soot, biodiesel, combustion

\section{Introduction}

Diesel engines are currently the largest source of power generation in the planet. They are widely used in quite different areas, as transportation and mining machinery. They are popular due to their high efficiency, low-cost and durability if compared with gasoline and other automotive fuels. ${ }^{1,2}$ Nevertheless, diesel engines also presents another remarkable feature: they are largely responsible by the emission of soot, one of most pollutants of environment. ${ }^{3}$

Soot is basically formed by particles of impure carbon, with diameter from 10 to $50 \mathrm{~nm}$. Due to its small size, soot particles can penetrate in the lung alveolus of human beings causing serious respiratory and cardiac diseases. ${ }^{4}$

Besides health and ecological issues, soot also plays an inconvenient role in the energy generation from combustion processes. ${ }^{5-7}$ In general, the presence of soot diminishes the overall efficiency of the combustion processes. Soot production is associated to the cracking reactions of hydrocarbon chains that generate carbon solid clusters. These reactions are carried out in gaseous phase and compete directly with the mechanism of oxidation of hydrocarbons that are responsible to the energy release. ${ }^{8}$ It means that soot is preferentially formed in fuel-rich and

*e-mail: 1tolomel@gmail.com high temperature combustion flames, as diffusive flames. These flames are largely used as industrial energy sources. In diffusive flames, as the fuel is burned using only the oxygen available from surroundings, soot presence is higher than the other kind of flames, like premixed ones In some specific applications, like boiler devices, however, a moderate amount of soot is desirable, as its presence increases the heat transfer rate. ${ }^{7}$ Soot is also quite important in the production of carbon black, which is employed as active filler in rubber products and as component of printing paints.

Among the strategies to reduce soot emission from diesel engines, recently a vegetable fuel, known as biodiesel, has been developed. ${ }^{9}$ Biodiesel is a kind of biofuel made by alkyl esters from long-chain fatty acids derived from vegetable oils or animal fat. Biodiesel shows a better flammability if compared to other biofuels, and can replace the diesel oil, or diesel/biodiesel blends, in compression ignition engines without significant changes. ${ }^{10}$ It also presents the following advantages over pure diesel: there are no aromatic compounds in its composition; it has a higher flashpoint; it is not toxic; it is biodegradable; and, finally, biodiesel produces less $\mathrm{CO}_{2}$ and $\mathrm{CO}$ emissions. ${ }^{11}$

The ability to detect soot in combustion systems is determinant to plan strategies for its reduction. Several techniques can be used for soot detection. One of the 
most common methods consists in the in situ collection of soot using membrane filters, followed by the analysis using gravimetric methods. ${ }^{9,12}$ However, in despite of its general employment, direct collection methods have some remarkable disadvantages. In several situations, the use of membrane filters causes a critical perturbation in the system, with significant changes of its original features. These methods present low spatial resolution, once the membranes accumulates soot from different region of the system. Finally, as the gravimetric analysis takes time, any kind of information about soot cannot be obtained promptly.

A viable alternative of the use of direct collection techniques is the optical or non-intrusive methods. The main feature of these techniques, as its name suggest, is the capability to detect soot at any point of the system with no remarkable perturbation. One of the most used optical methods is the absorption spectroscopy, which is based on the radiation absorbed by the particles. ${ }^{13}$ This method has a good spatial resolution, typically limited by the laser beam diameter, which allows the detection of soot concentration in different regions of the system. Methods based on light extinction ${ }^{6,9}$ and light scattering ${ }^{14}$ can also be used with similar performance. However, these three techniques require a set of signal treatments and a previous knowledge of the size particles which difficult the use of them as a real-time probe due to its low temporal resolution. For real-time monitoring, one can apply methods based on the soot incandescence, as laser-induced incandescence (LII). ${ }^{15-18}$

In this study, LII was used to investigate the behavior of soot emission in diesel diffusion flames by the addition of ethylic biodiesel fuel. The technique used for soot detection was the LII.

LII occurs when soot particles are irradiated by a high power laser and, as consequence, the temperature of particles increases far above the environment background. Figure 1 shows a detailed scheme concerning the LII process. Firstly, soot particles absorb the radiation from the laser beam. Then, a set of three competitive processes between each other may occur: (i) sublimation of particles; (ii) heat conduction to environment; (iii) emission of radiation. If the energy laser was kept below the sublimation threshold of soot particles, their temperature increases to a value much larger than the environment temperature. Under these conditions, soot particles spectrally behave as a blackbody, i.e., they emit a wide band radiation. This radiation is known as LII, and its intensity is proportional to the amount of soot illuminated, commonly expressed in terms of soot-volume fractions. ${ }^{8-10}$ This is a geometric property that plays an important role in the radiative characteristics and the temperature field of systems like a flame. In part, the development of the LII technique was motivated by the limitations of absorption measurements to determine soot-volume fractions.

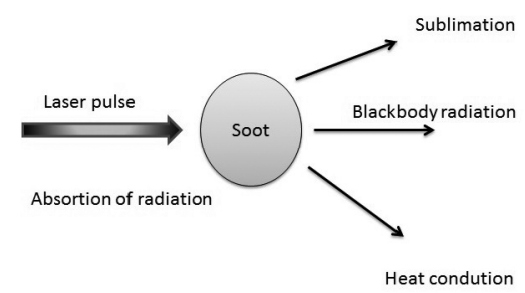

Figure 1. Process of absorption of radiation by the soot particles in a LII experiment.

Laser-induced incandescence has been applied both in qualitative measurements, as the determination of spatial distribution and of time-life measurements of soot, and in quantitative measurements, as the determination of soot particle size. ${ }^{19}$ LII has been applied for soot diagnostics in several practical devices: diesel engines, gas turbines, shock tubes, rocket engine and others. ${ }^{20-22}$ As other optical techniques, LII only requires a free spectral access to the region of interest. In closed vessels, this condition can be fulfilled with the installation of optical windows that does not absorb the laser radiation used as light source. The LII technique can also be used in velocity measurements of sooty flows, together with the technique of particle vaporization velocimetry (PVV). ${ }^{23}$

LII has the following remarkable advantages over other techniques of soot diagnostic: it is a non-intrusive technique, i.e., this method does not change the original characteristics of the investigated system; ${ }^{9}$ as the soot has a blackbody-like spectral behavior, several kinds of lasers can be used as excitation source, as long the laser has a fluence sufficiently high to promote the incandescence of soot particles; ${ }^{7}$ LII signal is not affected by changes in particles morphology; LII technique has high spatial and temporal resolution, once the incandescent signal from the illuminated region can be recorded in real-time..$^{20}$

Besides the free-access to soot, the implementation of LII requires attention to the laser fluence, the wavelength of source radiation, time and spectral intervals. The first two are related to the excitation process. A low-power laser may not be able to promote the fluorescence of soot, while a high power laser can lead to an excess of sublimation of the particles. The last ones are associated to the detection of LII signal. The use of near infrared (NIR) laser sources is recommended to avoid spectral interferences, mainly the fluorescence process from the PAHs (polycyclic aromatic hydrocarbons). The second harmonic of the Nd:YAG laser, at $532 \mathrm{~nm}$, promotes the undesirable fluorescence of large PAHs, which consists in the most interference of the LII 
signal, while the emission at $1064 \mathrm{~nm}$ excites only the soot particles. ${ }^{19,21}$ LII wavelength detection also have to take account spectral interferences derived of the natural flame emissions and light scattering effects..$^{20}$ Finally, the typical time-life of LII signal is ca. $1 \mu$ s, i.e., after this time-interval one observes a remarkable decrease of the incandescence signal.

\section{Experimental}

The flames were established from pure diesel (B0) and diesel/biodiesel blends using the following proportions in volume of ethylic biodiesel: 5\% (B5), 10\% (B10), 20\% (B20) and 50\% (B50). Commercial diesel, with sulfur concentration of $500 \mathrm{mg} \mathrm{kg}^{-1}$, was used in the experiments. The ethylic biodiesel was provided by the Fertibom ${ }^{\circledR}$ and is produced from a blend of bovine tallow (10\%) and vegetable oil $(90 \%)$. The burner used was a wick-fed lamp based on a model described in previous work. ${ }^{24}$ In all experiments, a period of about ten minutes was observed to ensure that the flame reach the steady-state where the fuel transport process was established by diffusion.

The LII experimental arrangement is shown in Figure 2. The source radiation was a pulsed Nd:YAG laser with maximum energy of $50 \mathrm{~mJ}$, model Quantel Twins, operating at the fundamental wavelength, $1064 \mathrm{~nm}$, with a repetition rate of $10 \mathrm{~Hz}$. The laser beam was focused using a convergent lens to increase the fluence. LII detection was performed by a photomultiplier Electrontube Laboratories, model EPM 28/135373-00, operating with a voltage of $900 \mathrm{~V}$. To avoid spectral interferences, LII signal was filtered using a monochromator Shoeffell, model GM 250, with a resolution of 1118 lines $\mathrm{mm}^{-1}$, set at $400 \mathrm{~nm}$. To improve the intensity of the collected signal, a convergent lens was used. The electrical signal was registered in an oscilloscope Agilent Technologies, model Infini vision LXI.

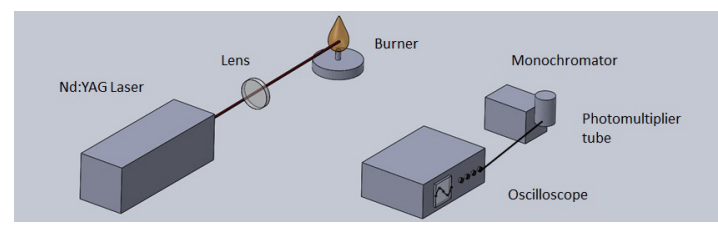

Figure 2. Scheme of the experimental arrangement of the LII technique.

Soot was detected in flames at two heights, at 80 and $260 \mathrm{~mm}$, considering the top of burner. At each one, the laser beam was focused in regions spaced by $1 \mathrm{~mm}$ over the full-width of flames, originating a horizontal mapping in both heights. All values of LII signal expressed in this work correspond to an average of at least 500 measurements recorded by the oscilloscope at each point.

\section{Results and Discussion}

All diffusion flames presented two distinct regions. The first one, placed immediately above the outlet of the wick and extending to the center of the flame, is characterized by the presence of the soot precursors and by a non-luminous behavior. In this region the soot precursors are present and the soot is not formed yet. ${ }^{25}$ The outer region has a pronounced yellow emission, due to thermal emission of soot in flame.

Figure 3 shows a typical time-dependent curve of LII intensity from flame, obtained from a B5 flame at $80 \mathrm{~mm}$ above the burner. The intensity of LII signal is proportional to the soot at the region irradiated by the laser. The shape of the curve gives information about the soot particles size.

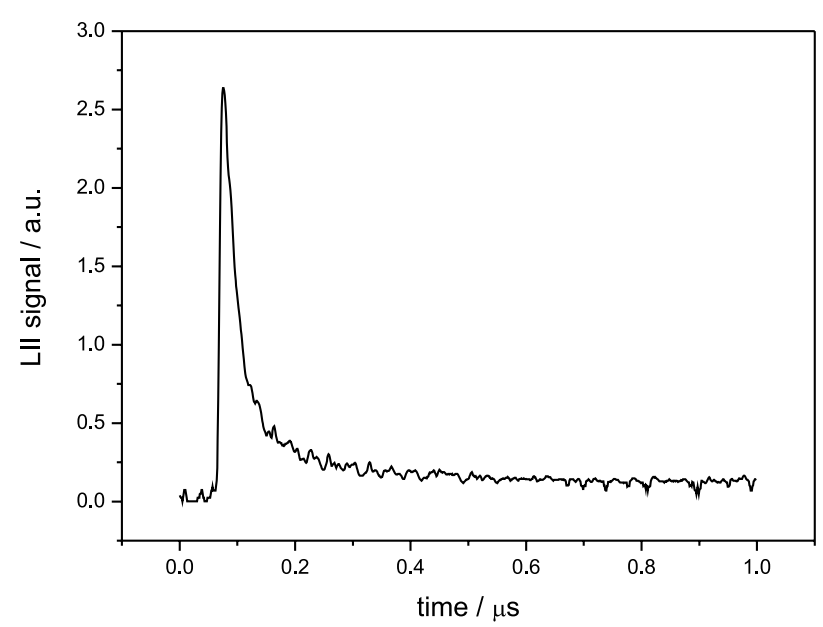

Figure 3. LII signal obtained from a B5 flame at $80 \mathrm{~mm}$ above the burner at the central region of horizontal axis of the flame (position zero).

The dependence of the LII intensity concerning the laser energy is shown in Figure 4. These measurements were acquired from a B5 flame at $80 \mathrm{~mm}$, but the other blends returned very similar results. One can observe that LII signal rises with the increasing of the fluence up to $0.4 \mathrm{~J} \mathrm{~cm}^{-2}$. Beyond this, the signal remains quite constant. This phenomenon, called saturation by laser intensity, is associated to the vaporization rate of soot. Up to $0.4 \mathrm{~J} \mathrm{~cm}^{-2}$, all input radiation energy is transferred to heat energy of soot particles, increasing the LII signal. Above this value, the excess of incident fluence increases the particle temperature over than the vaporization threshold, about $4000 \mathrm{~K}$. As result, the LII signal seems to be no longer affected by small variations from the fluence in this range. ${ }^{20}$ In the next flame mapping measurements, the laser fluence was set at $2.37 \mathrm{~J} \mathrm{~cm}^{-2}$.

The error bars observed in Figures 4-7 correspond to the standard deviation of the 500 measurements acquired in each point. This deviation is mainly due to the wavering 


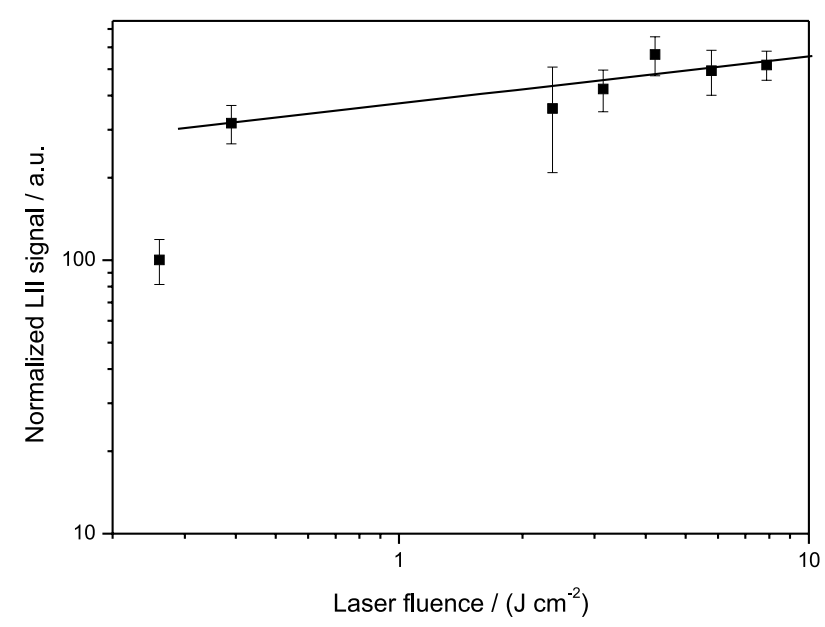

Figure 4. The dependence of the LII intensity concerning the laser fluence presented in logarithmic bases.

movement of the flame, which causes an instant changing in the amount of soot in the volume of flame hit by the laser beam and, as consequence, at the LII intensity.

Figure 5 shows the soot mapping at $260 \mathrm{~mm}$ obtained from flames of the pure diesel and biodiesel blends. One can notice that, for all flames investigated, the soot profiles presented a similar behavior, i.e, a symmetrical pattern around an intensity maxima localized at the center of flames, which was adopted as the abscissa axis origin. Once the LII signal is directly proportional to the soot amount, soot is preferentially formed at the region of $1 \mathrm{~mm}$ around the center of flames. As one moves away from the center of flames, toward the edges, LII signal decreases. As laser beam moves away from the center toward the flame edges, LII signal decreases. This phenomenon is due to the soot oxidation by the atmospheric oxygen gas in the surroundings of flames.

Figure 6 shows the soot distribution from the height of $80 \mathrm{~mm}$. On the contrary of the former results, one does

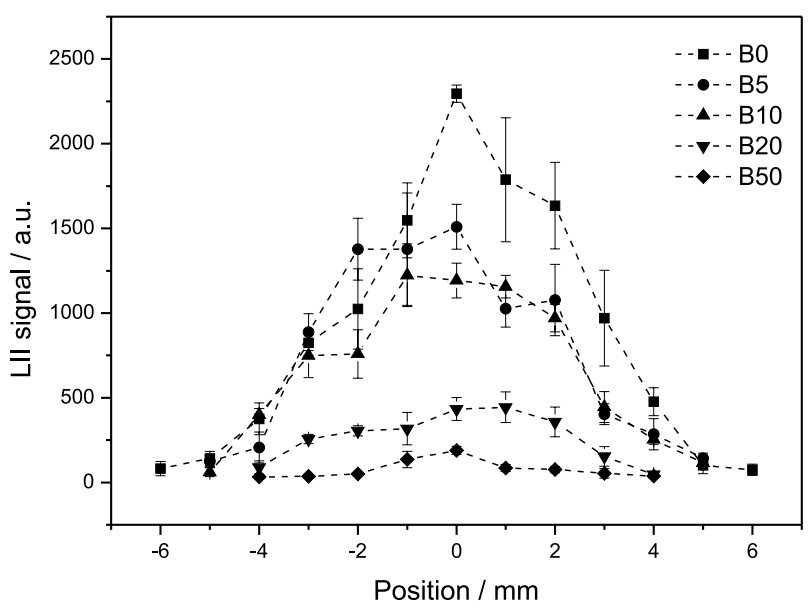

Figure 5. Soot distribution in flames of (a) B0; (b) B5; (c) B10; (d) B20; (e) B50 blends at the height of $260 \mathrm{~mm}$. not observe a peak at the center of flames. Instead of an unique maximum, LII curves show two slight maxima near the flame edges, with an occurrence of a minimum around the center. These results are in agreement with the existence of a non-luminous region in flames, characterized by the presence of the soot precursors known as polycyclic aromatic hydrocarbons, $\mathrm{PAH} .{ }^{26}$

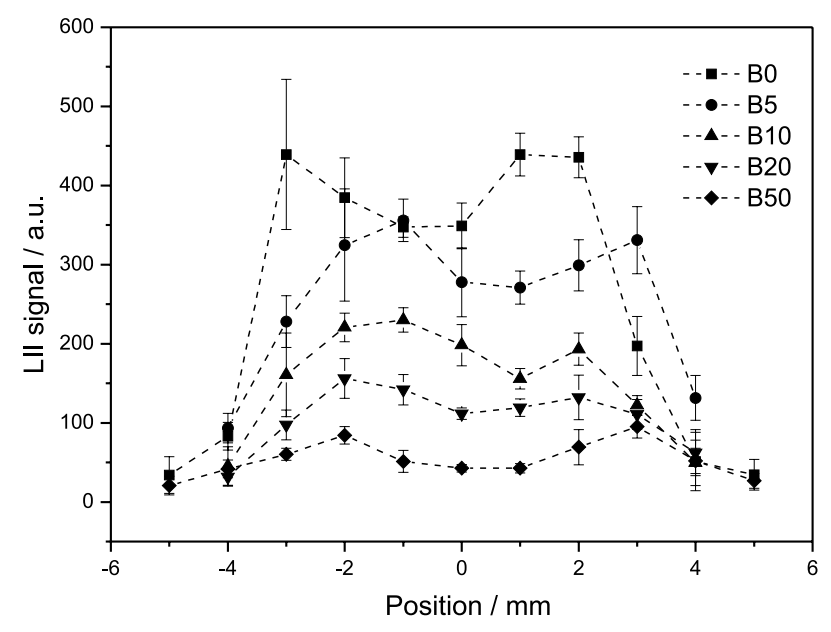

Figure 6. Soot distribution in flames of (a) B0; (b) B5; (c) B10; (d) B20; (e) B50 at $80 \mathrm{~mm}$ above the burner.

Both Figures 5 and 6 show an important effect of the addition of biodiesel to the diesel fuel: the decrease of soot production in flames. This relationship can be better visualized if one takes the maximum values of LII signal from soot mapping. These values correspond to the average of LII signal at the center of flames in the Figure 5 ( -1 to $1 \mathrm{~mm})$ and to the average of the symmetrical edges of the Figure 6 ( -2 and $2 \mathrm{~mm}$ ). Thus, Figure 7 shows an inverse linear relationship between LII signal and the biodiesel amount up to B20 blends for both flame heights.

At $260 \mathrm{~mm}$, the addition of a volumetric amount of 5\% of biodiesel produces an average decrease of ca. 30\% in LII signal. However, the addition of a fraction of $10 \%$ leads to a small average decrease of ca. 35\%, which indicates a kind of initial threshold concerning the biodiesel addition. The closeness of LII values between B5 and B10 blends was also reported by Tran et al. ${ }^{24}$ In B20 blends, the soot decrease achieves ca. $80 \%$ if compared to pure diesel flames. This value is slightly lower to the maximum decrease observed in B50 blends, which indicates a flat behavior of the addition of biodiesel. Indeed, the extrapolation of both regions observed in Figure 7 returns a saturation threshold of ca. $22 \%$ concerning the addition of biodiesel.

The curve slope value from LII signal shows that the impact of biodiesel addition on soot reduction is less pronounced at flame height of $80 \mathrm{~mm}$. This behavior can be attributed to the more pronounced presence of atmospheric 
oxygen in the flame edges if compared to the oxygen originated from the biodiesel chain, and can illustrate the advantages of the in situ feature of LII technique. Studies showed that oxygenated fuels can suppress the soot in its formation due to $\mathrm{OH}$ and $\mathrm{O}_{2}$ originated from the fuel chain. ${ }^{27}$

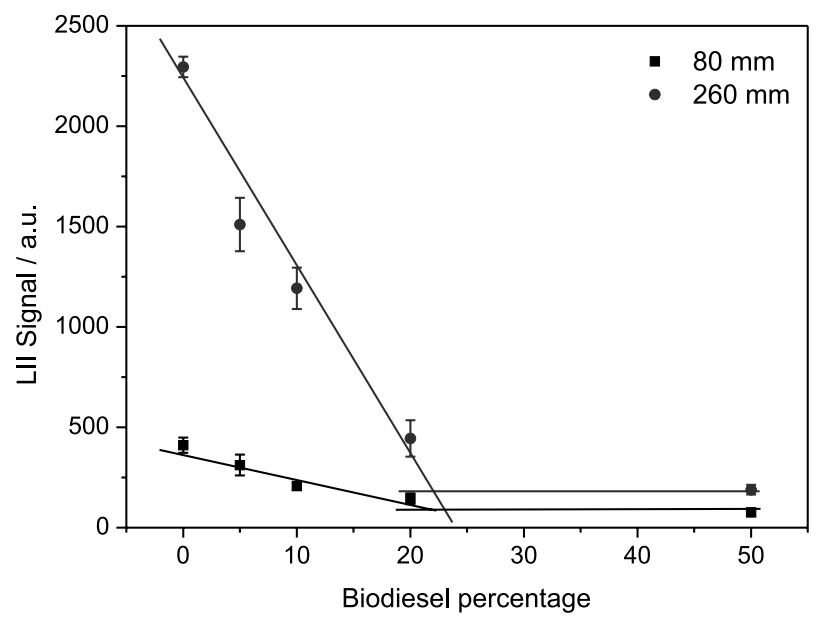

Figure 7. The LII intensity concerning the biodiesel addition in blends at 80 and $260 \mathrm{~mm}$ above the burner.

\section{Conclusions}

Laser-induced incandescence was used to evaluate soot formation in pure diesel and diesel/biodiesel flames. The LII values showed a remarkable decrease on soot production with the increase of the volumetric amount of biodiesel up to ca. $22 \%$. Beyond this value, one observes a saturation behavior of the LII values. Despite this the reduction of soot formation was significantly different in the two flame heights investigated, the threshold of biodiesel addition remains almost the same one. This result confirms that the action of the biodiesel is more remarkable on soot suppression, through the $\mathrm{OH}$ species, and not by soot oxidation.

\section{Acknowledgments}

The authors thank to CAPES for the fellowships and FINEP, covenant 01.11.0069.00, for financial support.

\section{References}

1. Neeft, J. P. A.; Makkee, M.; Moulijn, J. A.; Fuel Process. Technol. 1996, 47, 1.

2. Braun, S.; Appel, L. G.; Schmal M.; Quim. Nova 2003, 27, 472.

3. Williams, A.; Prog. Energy Combust. Sci. 1976, 2, 167.

4. Carvalho, J. A.; Lacava, P. T.; Emissões de Poluentes em
Processos de Combustão, $1^{\mathrm{a}}$ ed.; Editora UNESP: São Paulo, Brazil, 2003.

5. Bockhorn H.; Fetting F.; Wenz, H. W.; Ber. Bunsen-Ges. Phys. Chem. 1983, 87, 1067.

6. Mansurov, Z. A.; Combust. Explos. Shock Waves 2005, 41, 727.

7. Vander Wal, R. L.; NASA/CR 97-206325, Using Laser-Induced Incandescence to Measure Soot/Smoke Concentration; NASA: Ohio, 1997. Available at http://ntrs.nasa.gov/archive/nasa/casi. ntrs.nasa.gov/19980013404.pdf, accessed in November 2016.

8. Barreta, L. G. In Métodos Experimentais de Análise Aplicados à Combustão, $1^{\mathrm{a}}$ ed.; Lacava, P. T.; Martins, C. A., eds.; Papel Brasil: Taubaté, Brazil, 2010.

9. Choi, M. Y.; Mulholand, G. W.; Combust. Flame 1995, 102, 161.

10. Altin, R.; Çetinkaya, S.; Yücesu, H. S.; Energy Convers. Manage. 2001, 42, 529.

11. Ferrari, R. A.; Oliveira, V. D.; Scabio, A.; Quim. Nova 2005, $28,19$.

12. Wal, R. L. V.; Zhou, Z.; Choi, M. Y.; Combust. Flame 1996, 105,462 .

13. D'Alessio, J.; Lazzaro, M.; Massoli, P.; Moccia, V.; Opt. Lasers Eng. 2002, 37, 495.

14. Oltmann, H.; Reimann, J.; Will, S.; Combust. Flame 2010, 157, 516.

15. Vander Wal, R. L.; Weiland, K. J.; Appl. Phys. B 1994, 59, 445.

16. Melton, L. A.; Appl. Opt. 1984, 23, 2201.

17. Witze, P.; Shirish, S.; Durrett, R.; Farrell, L.; JSME Int. J., Ser. B 2005, 48, 632 .

18. Caetano, N. R.; Pereira, F. M.; Vielmo, H. A.; van der Lann, F. T.; Mod. Mech. Eng. 2013, 3, 137.

19. Manzzelo, S. L.; Lenhert, D. B.; Yozgatligil, A.; Donovan, N. T.; Mulholland, G. W.; Zachariah, M. R.; Tsang, W.; Proc. Combust. Inst. 2007, 31, 675.

20. Vander Wal, R. L.; Appl. Phys. B 2009, 96, 601.

21. Park, J.; Ryoo, H. C.; Chun, H. S.; Song, S.; Hahn, J. W.; Chun, K. M.; JSME Int. J., Ser. B 2006, 49, 1351.

22. Viskup, R.; Measurement 2014, 58, 429.

23. Seitzman, J. M.; Wainner, R. T.; Yang, P.; Opt. Lett. 1999, 24 , 1632.

24. Tran, M. K.; Dunn-Rankin, D.; Pham T. K.; Combust. Flame 2012, 159, 2181.

25. Gaydon, A. G.; Wolfhard, H. G.; Flames, $3^{\text {rd }}$ ed.; Chapman and Hall: London, 1970.

26. Moreau, S. C.; Thersen, E.; Mercier, X.; Pawels, J. F.; Desgroux, P.; Appl. Phys. B 2004, 78, 485.

27. Cai, G.; Yen, M.; Abraham, J.; Chem. Eng. Sci. 2016, 144, 249.

Submitted: August 26, 2016

Published online: November 29, 2016 